\title{
TURISMO E RESPONSABILIDADE SOCIAL: ANÁLISE DO PROGRAMA BERIMBAU DA COSTA DO SAUÍPE
}

\author{
Marco Aurélio Avila ${ }^{1}$ \\ Gustavo da Cruz ${ }^{2}$ \\ Jahumara Gloria Téllez González ${ }^{3}$ \\ Universidade Estadual de Santa Cruz - Bahia
}

\begin{abstract}
Resumo: A construção do empreendimento turístico Costa do Sauípe, na Bahia, provocou visíveis mudança nas relações sociais, econômicas e ambientais da região no início das suas atividades. Diante dessa situação, surgiu o Programa Berimbau, para atuar como braço social do empreendimento junto às comunidades do seu entorno. Com o objetivo de analisar como as ações de responsabilidade social do Programa Berimbau têm sido utilizadas como instrumento de desenvolvimento nas comunidades do entorno da Costa do Sauípe, foi realizado um estudo de caso, através de uma pesquisa quali-quantitativa, das oito comunidades do entorno do empreendimento, atendidas pelo Programa. Foi possível concluir que, apesar das suas limitações, a implantação do Programa Berimbau teve um resultado positivo, tornando o empreendimento Costa do Sauípe o principal agente de desenvolvimento para as comunidades do seu entorno.
\end{abstract}

Palavras-chave: Turismo, Responsabilidade Social, Desenvolvimento Sustentável, Programa Berimbau, Costa do Sauípe.

Resumen: Turismo y responsabilidad social: análisis del Programa Berimbau de Costa do Sauípe (Bahía, Brasil).

La construcción del complejo turístico Costa do Sauípe, en Bahía (Brasil), provocó visibles cambios en las relaciones sociales, económicas y ambientales de la región al inicio de sus actividades. Ante esa situación, surgió el Programa Berimbau para actuar como brazo social del complejo junto a las comunidades de su entorno. Con el objetivo de analizar cómo las actuaciones de responsabilidad social del Programa Berimbau han sido utilizadas como instrumento de desarrollo en las comunidades del entorno de Costa do Sauípe, se hizo un estudio de caso, a través de una investigación cuali-cuantitativa, de las ocho comunidades del entorno del complejo, atendidas por el Programa. Así fue posible concluir que, a pesar de sus limitaciones, la implantación del Programa Berimbau tuvo un resultado positivo, convirtien-

1 Doutor em Turismo e Desenvolvimento Sustentável pela Universidade de Las Palmas de Gran Canária ULPGC - Espanha. Professor adjunto da Universidade Estadual de Santa Cruz. Coordenador do Mestrado em Cultura e Turismo - UESC. Email: marco@ativanet.com.br

2 Doutor em Turismo e Sustentabilidade pela Universidade de Las Palmas de Gran Canária - Espanha. Atualmente é professor e vice-coordenador do Mestrado em Cultura e Turismo da Universidade Estadual de Santa Cruz - Bahia. E-mail: gusdacruz@hotmail.com

3 Mestre em Cultura e Turismo pela Universidade Estadual de Santa Cruz. Email: gloria.cepedi@gmail.com 
do el complejo Costa do Sauípe en el principal agente de desarrollo para las comunidades de su entorno.

Palabras clave: Turismo, Responsabilidad Social, Desarrollo Sostenible, Programa Berimbau, Costa do Sauípe.

\begin{abstract}
Tourism and social responsibility: Analysis of the Berimbau Programme of la Costa do Sauípe (Brazil).

The construction of the tourism complex in Costa do Sauípe, in Bahía (Brazil) led to visible changes in the social, economic and environmental relationships in the region when it began its activities. This gave rise to the Berimbau Programme which acted as the complex's social arm together with the surrounding communities. A case study was carried out with the aim of analysing how the social responsibility actions of the Berimbau Programme have been used as an instrument for development in the communities surrounding Costa do Sauípe. Qualitative/quantitative research was carried out on the eight communities surrounding the tourism complex which are served by the Programme. We can conclude that, despite its limitations, the implementation of the Berimbau Programme had a positive result, converting the Costa de Sauípe complex into the main agent for development for the surrounding communities.
\end{abstract}

Key words: Tourism, Social Responsibility, Sustainable Development, Berimbau Programme, Costa do Sauípe.

\title{
1. INTRODUÇÃO
}

O tema responsabilidade social foi inicialmente abordado na literatura nas primeiras décadas iniciais do século XX, diante da incapacidade dos modelos liberais e neoliberais, de equacionar os desafios sociais de liberalismo econômico. Ao ganhar peso e poder, as empresas tiveram que ampliar sua responsabilidade perante a sociedade, já que a humanidade começou a demandar um novo modelo de crescimento, onde o papel das empresas não se restringe a geração de empregos e pagamento de salários, mas sim um desenvolvimento econômico que não implique na degradação do ambiente e que a prosperidade deve ser eqüitativa e redutora das desigualdades. (Scour, 1998; Swarbrooke, 2000)

Segundo Ashley (2002), a responsabilidade social empresarial, que inicialmente surgiu em forma de ações de altruísmo, passou a ser um diferencial, uma vantagem competitiva decorrente, em grande medida, da maior conscientização do consumidor com respeito ao papel social das empresas. Desta maneira, acrescenta-se de forma eqüitativa poder social ao poder econômico das empresas. Assim, quanto maior for o poder econômico da empresa, maior deve ser a sua responsabilidade social.

Partindo desta idéia, pode-se destacar a importância que tem a responsabilidade social no setor turístico, que situado entre os três setores econômicos mais importantes da economia global, é responsável por aproximadamente $10 \%$ do PIB mundial, empregando mais de 221 milhões de pessoas no mundo todo. A tendência do setor é de manter essa liderança com uma taxa de crescimento anual média de $6,5 \%$, chegando a movimentar 1.560 milhões de pessoas anualmente, em 2020. (OMT, 2006)

Assim, a preocupação de como aproveitar os benefícios do desenvolvimento do turismo de forma mais eqüitativa, não é uma questão ideológica e sim prática e de extrema necessidade. Pois como o turismo é uma atividade socioeconômica capitalista, orien- 
tada pelo lucro, geralmente não traz desenvolvimento. Segundo Araújo (2006), ao provocar um crescimento econômico rápido e desordenado, desencadeia um processo integrador, mas, ao mesmo tempo, desintegrador, que provoca rupturas sociais e ambientais.

Por outro lado, segundo o mesmo autor, as comunidades criam muitas expectativas com respeito ao desenvolvimento do turismo na região onde moram. Uma das principais ilusões da comunidade "é acreditar que a expansão das atividades do turismo vai solucionar os problemas socioeconômicos que os atingem." (Araujo, 2006, p.159)

No entanto, segundo Beni (2006, p. 48), quando se instalam grandes complexos hoteleiros numa localidade, principalmente se esta é pequena e de economia estagnada, constata-se uma brusca ruptura nas condições de existência, criando uma situação para a qual a comunidade não está preparada. Assim surgem relações sociais de natureza contraditória que, eventualmente, geram a rejeição do turismo por parte da população autóctone e residente.

Foi essa a situação que enfrentou o empreendimento turístico Costa de Sauípe, localizado no município Mata de São João, no litoral norte da Bahia, quando o trauma causado às comunidades do entorno, pela sua implantação, começou a ter repercussões no seu funcionamento.

A medida que novas estradas ligavam as cidades ao empreendimento, o isolamento foi diminuindo gradativamente e começou a se desenvolver o turismo na região. Foram difundidos serviços básicos como eletricidade, água encanada e esgoto sanitário; e novas atividades econômicas começaram a surgir. $\mathrm{O}$ turismo solidificou-se rapidamente como a principal atividade econômica da região, mas não conseguiu oferecer uma opção viável para o desenvolvimento socioeconômico sustentável das populações locais.

Assim, o início da operação do empreendimento Costa do Sauípe, ao mesmo tempo em que trouxe emprego e renda, provocou impactos sócio-ambientais que mostraram a necessidade de adoção de um modelo sustentável de desenvolvimento do turismo.

As ofertas de trabalho e emprego não atingiram significativamente as parcelas mais pobres da população, desqualificada para atender um público exigente com relação aos serviços oferecidos. A precariedade em termos de infraestrutura e serviços básicos permaneceu na maioria das comunidades, apesar do significativo incremento da arrecadação municipal. Além disso, a promessa da sustentabilidade ambiental da região não se efetivou, pelo contrário: os recursos naturais começaram a ser desgastados pelo desenvolvimento turístico.

Além disso, a ruptura produzida no dia-a-dia da região, antes de caráter estritamente rural, submeteu as populações, de baixo nível de instrução a um novo ritmo de vida, trazendo muitas dificuldades e poucos benefícios.

A rapidez das mudanças ocasionadas pelo turismo na região gerou efeitos negativos nas relações sociais e na qualidade de vida da população já que e os benefícios esperados não eram sentidos. Os interesses do empreendimento com os da população não foram articulados, bem como a atividade turística não foi conciliada com as outras atividades produtivas locais. Desta forma, a comunidade começou a se opor ao desenvolvimento das atividades turísticas na região, iniciando uma fase de risco social que ameaçou o sucesso e o desempenho econômico do empreendimento. 
Esse conjunto de fatores fez crescer a preocupação de diversas entidades, públicas ou não, sobre o futuro da região. Organizações como o Instituto de Hospitalidade (IH), o Sebrae e a Fundação Banco do Brasil empenharam-se em promover estudos e elaborar ações que tentassem minimizar os impactos socioeconômicos e ambientais negativos desse abrupto crescimento populacional e pudessem promover melhorias na qualidade de vida das comunidades.

Diante dessas circunstâncias, a administração da Costa do Sauípe percebeu a necessidade de aprofundar suas relações com as comunidades circunvizinhas, com vistas a minimizar os custos sociais do desenvolvimento do turismo na região (DESENCOM, 2005).

O Programa Berimbau lançado em julho de 2003, resultado de parceria entre a Costa do Sauípe, a Fundação Banco do Brasil e a Previ (Caixa de Previdência dos Funcionários do Banco do Brasil), teve suas linhas gerais desenhadas a partir da discussão com os moradores das comunidades, tentando favorecer o máximo possível a autodeterminação das comunidades, assegurando-lhes a possibilidade de participação nos processos decisórios.

Neste contexto, esse estudo buscou investigar de que forma o Programa Berimbau tem contribuído para o desenvolvimento sócio-econômico das comunidades do entorno da Costa do Sauípe, três anos após sua implantação.

O objetivo geral que norteia este estudo é analisar como as ações de responsabilidade social do Programa Berimbau têm sido utilizadas como instrumento de desenvolvimento nas comunidades do entorno da Costa do Sauípe. Partindo desse principio, complementam o estudo os seguintes objetivos específicos:

- Compreender o contexto social local antes da implantação do empreendimento.

- Identificar os impactos causados pela implantação do empreendimento.

- Identificar as ações de responsabilidade social do empreendimento no âmbito do programa.

- Fazer recomendações de estudos e projetos que possam colaborar com o aperfeiçoamento do programa visando aumentar sua eficiência e sustentabilidade.

\section{RESPONSABILIDADE SOCIAL E TURISMO}

Uma nova filosofia de gestão empresarial está se tornando uma forte vantagem competitiva, baseada em princípios como ética, cidadania e solidariedade: a responsabilidade social. Desta forma, ser "socialmente responsável" para as empresas vem se tornando um dos pilares de sustentação dos negócios, tão importante quanto a qualidade, a tecnologia e a inovação. (Fontes, 2005)

Frente a esta nova filosofia surgem duas correntes de pensamento. Uma pressupõe que os problemas sociais são de responsabilidade única dos governos e afirmam que, o alcance de um bom resultado financeiro é a principal função social da empresa, baseando seus argumentos, principalmente, nas teses de Milton Friedman (1970) sobre direito 
de propriedade. Considera que o papel social da empresa deve se restringir a gerar empregos, pagar salários justos e manter seus impostos em dia.

A outra corrente considera que empresas andam à frente dos governos e que por tanto devem ser parte ativa da solução dos problemas da sociedade. Deste ponto de vista as responsabilidades da empresa, para com a sociedade, extrapolariam as ações fiscais e tributárias, adotando uma nova perspectiva que prioriza a rentabilidade sem esquecer da necessidade de proteger o meio, tanto natural quanto social e cultural.

A responsabilidade social empresarial começou mostrando-se, inicialmente, em forma de ações de altruísmo egoísta. A maioria das ações de consciência social só se realizavam se as empresas se beneficiavam financeiramente com elas. Investir em ações socialmente responsáveis era considerado um aumento de custos para as empresas. Paulatinamente, as empresas foram se conscientizando da importância das ações de responsabilidade social, ficando mais atuantes e comprometidas.

De uma forma muito clara, Voigt (2006, p.3) consegue descrever esse grande salto evolutivo:

Originariamente assistencialista, a ação social das organizações empresariais brasileiras observa uma substancial mudança a partir do final da década de 80 e, com maior ênfase, no início dos anos 90. É nesse período que o envolvimento das empresas com a área social começa a ser feito de maneira estratégica e a ganhar a dimensão que tem hoje. Quando realizam um investimento social, as empresas acompanham de perto a implementação dos projetos que operam ou financiam, querem saber quais foram as mudanças obtidas nas condições sociais existentes antes de sua intervenção e se os recursos estão sendo aplicados com responsabilidade e eficiência. Para isso, diretamente ou por meio de seus institutos ou fundações, utilizam como parâmetro suas origens e adaptam conceitos, procedimentos e metodologias - aplicados com sucesso no mundo empresarial - na execução de projetos sociais.

Assim, pode-se deduzir que a definição da "Responsabilidade Social" parte de uma ampla gama de interpretações, que vão desde as idéias de obrigação legal e dever fiduciário, até o comportamento ético ou a contribuição caridosa, o que torna complexa a tarefa de definir responsabilidade social.

Partindo dessas idéias, pode se conceituar de uma forma ampla, a responsabilidade social como sendo "a obrigação da administração de tomar decisões e ações que irão contribuir para o bem-estar e os interesses da sociedade e da organização" (Daft, 1999, p. 88) ao que Oliveira (1984) acrescenta, considerando os valores, normas e expectativas da sociedade para o alcance de seus objetivos como empresa.

De uma forma mais detalhada, responsabilidade social pode ser definida, segundo Ashley (2002, p. 6), como:

O compromisso que uma organização deve ter para com a sociedade, expresso por meio de atos e atitudes que a afetem positivamente, de modo amplo, ou a alguma comunidade, de modo específico, agindo proativamente e coerentemente no que tange a seu papel específico na sociedade e a sua prestação de contas para com ela. 
No presente estudo, baseado nas idéias desses autores, o termo responsabilidade social será abordado como sendo uma resposta das empresas às necessidades sociais, de forma a se tornar parceira e co-responsável pelo desenvolvimento econômico - social e pela proteção do meio ambiente. Numa visão expandida, como coloca Ashley (2002), responsabilidade social será entendida como toda e qualquer ação das empresas que possam contribuir para a melhoria da qualidade de vida da sociedade.

Com isso, segundo Guedes (2000, p. 57), uma empresa que age com responsabilidade social:

aumenta o seu relacionamento com diversos públicos relevantes (clientes atuais e em potencial, opinião pública, acionistas, investidores, fornecedores, funcionários, governo), aumenta a exposição positiva em mídia espontânea onde seus produtos, serviços e marca ganham maior visibilidade e possível aceitação.

Como conseqüência, para Rico (2007), a empresa teria o reconhecimento institucional, comunitário e social; através da construção de uma imagem positiva por meio de um investimento social que contribuiu diretamente para a melhoria da vida da comunidade.

Após essas abordagens iniciais, tem-se o seguinte questão: existe uma verdadeira vontade por parte das empresas turísticas de desempenhar esse novo papel?

Este tema é bastante polêmico, pois existem diversas empresas turística que divulgam demasiadamente suas ações, minando com o seu desejo de lucro, a imagem de empresas realmente responsáveis. Surgindo assim muitos questionamentos sobre a importância da responsabilidade social empresarial ao serem levantadas dúvidas sobre os possíveis motivos que levariam às empresas a se envolver nessa área, atribuindo a responsabilidade social uma conotação puramente de marketing.

Contudo, Ashley (2002) afirma que no Brasil, as empresas convivem por um lado com os princípios éticos racionais capitalistas de padrão internacional que define parâmetros de profissionalismo, imparcialidade, credibilidade e transparência.

No entanto, embora exista a tendência das empresas turísticas reconhecerem a importância de assumir suas obrigações morais com a sociedade, isso não ocorre de uma forma totalmente voluntária e natural. Segundo Ashley (2002), decorre, em grande medida, da maior conscientização do consumidor com respeito ao papel social das empresas e do conseqüente aumento da procura por produtos e práticas que gerem melhoria para o meio ambiente ou para a comunidade, valorizando aspectos éticos ligados à cidadania.

Apesar dos dados apresentados anteriormente sobre o crescimento econômico, este não pode ocorrer distanciado do desenvolvimento social, ou seja, os empreendimentos turísticos não podem ficar ilhados da comunidade que os acolheu. Beni $(2002$, p.79) é eloqüente ao descrever a relação que, geralmente os resorts têm com a comunidade:

são instalações suntuosíssimas, de arquitetura clássica ou moderna, arrojadas, mas que, em alguns casos não deixam de agredir o conjunto paisagístico da área onde se instalam. Pela própria imponência das edificações e grande luxo de suas instalações já provocam um efeito de constrangimento e separação social entre os visitantes e as populações das cidades próximas, reproduzindo, no presente, a distância dos senhores feudais e sua corte em relação ao povo a aos vassalos. 
Swarbrooke (2000) ressalta a que os resorts levam os turistas a acreditarem que não há razão para deixar o complexo durante sua permanência ali, o que reduz as oportunidades de os comerciantes locais venderem seus produtos e serviços para os turistas.

Os conceitos Desenvolvimento Sustentável e Responsabilidade Social, muitas vezes se confundem para expressar uma mesma idéia, uma postura por parte das empresas que tem em conta não só os aspectos econômicos, mas também os aspectos sociais e ambientais.

Essa convergência de conceitos é claramente observada no documento Criando Valor publicado pelo Instituto Ethos (2003, p.6):

A sustentabilidade é as vezes chamada responsabilidade social corporativa ou cidadania corporativa. Embora usemos aqui a palavra sustentabilidade, reconhecemos que em muitos pontos os termos são sinônimos e cobrem os mesmos amplos aspectos dos negócios: a gestão, o modo de tratamento dos empregados, o impacto sobre o meio ambiente e sobre a comunidade local e as relações com os fornecedores e clientes.

Observa-se que o Desenvolvimento Sustentável e Responsabilidade Social partem de uma mesma premissa, apesar de terem origens diferentes e percorrendo caminhos diferentes possuem o mesmo ponto de chegada, ou seja, uma empresa que se diz socialmente responsável tem de se reger pelos princípios do Desenvolvimento Sustentável e uma empresa que se rege pelos princípios do Desenvolvimento Sustentável é uma empresa responsável socialmente.

Muitas empresas do setor turístico estão começando a desenvolver projetos de grande impacto e relevância. Entre elas podem se destacar as ações das redes hoteleiras Sheraton, que tem um programa dedicado a crianças carentes; a Intercontinental, que arrecada fundos para programas de saúde e vacinação; a rede Blue Tree Hotels, que criou um programa de solidariedade destinado a cooperar com a Liga Feminina de Combate ao Câncer; a Accor e a Transamérica que, além de terem seus programas sociais, são patrocinadoras de iniciativas como o prêmio Bem Eficiente, dirigido às entidades que trabalham na filantropia nacional; entre muitas outras.

\section{PROCEDIMENTOS METODOLÓGICOS}

Inaugurada em outubro de 2000, a Costa do Sauipe, ocupa uma área de 1 milhão e 720 mil m², com $141 \mathrm{mil} \mathrm{m}^{2}$ construídos, contando com um total de 1.617 unidades habitacionais, numa extensão de $6 \mathrm{~km}$ de praia. O empreendimento, enquadrado na categoria de resort, recebe cerca de 150 mil turistas por ano, que podem usufruir de cinco hotéis, operados por três redes internacionais: Marriott (EUA), Accor (França) e SuperClubs (Jamaica), seis pousadas temáticas, um centro comercial de entretenimento com seis bares, três restaurantes, trinta e três lojas, duas agências de turismo, um centro ecumênico, além de um campo de golf de padrões internacionais, um centro de tênis com 15 quadras de tênis, duas de squash e quatro quadras de paddle, um centro esportivo com quatro quadras poliesportivas e campo de futebol society, um centro eqüestre e uma lagoa para prática de esportes náuticos. 
Segundo dados da Sauípe S.A, no empreendimento são empregadas 2,4 mil pessoas, sendo $40 \%$ da mão-de-obra formada por habitantes da região, somente para os cargos mais baixos, devido ao despreparo dos moradores e ao baixo índice de escolaridade local (Sauipe S.A.).

Trata-se de um estudo de caso, com abordagem quali-quantitativa, em que foram empregados tanto instrumental estatístico na análise dos dados coletados, quanto obtendo dados descritivos sobre as pessoas, o lugar e os processos de mudança procurando compreender os fenômenos segundo a perspectiva dos participantes da situação em estudo (Godoy, 1995).

Sendo o Programa Berimbau o objeto de estudo desta pesquisa, o universo a ser pesquisado correspondeu às oito comunidades do entorno do empreendimento Costa do Sauípe, atendidas pelo programa, sendo Diogo, Santo Antônio, Areal, Curralinho e Vila Sauípe, no município de Mata de São João e Estivas, Canoas e Porto de Sauípe, no município de Entre Rios.

O tipo de amostra não probabilística a ser utilizado foi definido levando em conta o tipo de pesquisa, a acessibilidade aos elementos da população, a disponibilidade ou não de ter os elementos da população, a representatividade desejada ou necessária, a oportunidade apresentada pela ocorrência de fatos ou eventos, a disponibilidade de tempo, recursos financeiros e humanos etc. (Mattar, 1996, p. 133)

Segundo Gil (1999, p.119), neste tipo de pesquisa, é recomendável a realização entrevistas informais com "informantes-chaves, que podem ser especialistas no tema em estudo, líderes formais ou informais, personalidades destacadas, etc." o que levou à escolha da amostragem de seleção racional ou intencional. Já no caso dos questionários foi realizada amostragem por conveniência ou acidental, por permitir selecionar os membros da população mais acessíveis.

O tamanho da amostra foi delimitado seguindo os princípios definidos por Hayes (1996), para a avaliação de projetos de desenvolvimento. Para este autor o caráter local deste tipo de projeto, faz com que as pessoas afetadas sejam mais homogêneas, pelo que uma amostra de 20 pessoas, sempre que seja evitada a discriminação na amostra, é suficiente, se o interesse da pesquisa estiver voltado apenas para mudanças distintamente observáveis.

Assim sendo, para a aplicação dos questionários, foi definida uma amostra composta por 50 (cinqüenta) moradores da região. Paralelamente foram escolhidas 10 (dez) pessoas para serem entrevistadas, em razão de serem pessoas representativas do local, divididas em três grupos distintos sendo 06 (seis) moradores, 02 (dois) líderes comunitários e 02 (dois) dirigentes do Sauípe S.A.

A pesquisa de campo foi realizada no período de 19 a 25 de junho de 2006 e os instrumentos foram aplicados pela própria pesquisadora. Para obter as informações primárias, foram utilizadas a observação individual não participante em ambiente natural, a aplicação de questionários e a realização de entrevistas semi-estruturadas. Para cada grupo foi elaborado um roteiro de entrevista diferenciado, sendo 13 perguntas para moradores, 14 para líderes comunitários e 17 para dirigentes. 
Posteriormente a medição e tabulação, foram analisados e interpretados de forma descritiva e analítica os dados adquiridos. O que possibilitou confrontar a teoria e a realidade, ou seja, fazer uma relação entre as referencias teóricas e os resultados obtidos. Desta forma, foi possível levantar certos itens relevantes e discussões pertinentes ao tema, conforme apresentado no tópico seguinte.

\section{RESULTADOS E DISCUSSÕES}

Durante as entrevistas, tanto dos moradores quanto dos líderes comunitários, foi identificada, nas verbalizações dos entrevistados, a importância que os moradores dão à possibilidade que tiveram de participar no planejamento e implementação do Programa, o que favoreceu a sua legitimação e aceitação.

Foi compensador escutar a clareza com que J.A.P., um dos líderes comunitários enxerga a situação enfrentada:

"Houve um certo respeito na implantação. Houve até uma audiência pública, contando as informações, agora nós contamos também com uma população que não entendia, a pessoa por não ter conhecimento, não ter estudo, e acharam que aquilo era a salvação da lavoura, todo mundo achava que seria empregado, mas o nosso povo não tinha segundo grau, não tinha conhecimento de inglês, não tinha conhecimento de informática, não fala inglês, não fala espanhol, e não era qualificado nem na área de hotelaria mesmo, os básico de cozinha e etc. Então não se podia aguardar que havia emprego para todos. Aí, a salvação foi realmente o programa, que hoje tá lá qualificando esse pessoal mesmo não tendo vaga, essas pessoa vai trabalhar em outras atividades que vai fornecer ao próprio sistema hoteleiro."

As respostas com respeito ao impacto ambiental foram bem ambíguas, mostrando desconhecimento e desinteresse sobre o tema. Já sobre a possibilidade de solicitar melhorias do Programa se mostraram bastante céticos, achando que "já está bom do jeito que é" e que talvez se eles solicitassem alguma outra coisa não seriam atendidos ou até poderiam ser taxados de ingratos, como coloca N.J.L.S. "magina, se com a ajuda do Berimbau nós criamos a cooperativa, nós já até temos uma sede alugada".

A avaliação final, que essas pessoas têm do empreendimento e do Programa, é totalmente positiva, citando entre os principais benefícios, a geração de emprego e renda, a criação de infra-estrutura, o fortalecimento das associações e a viabilização da participação em feiras e eventos para apresentação de produtos.

A opinião geral quanto ao empreendimento e ao Programa Berimbau foi altamente positiva. Isto mostra que os argumentos utilizados pelos defensores do turismo convencem, e geram na população local, as perspectivas de empregos e melhores ganhos, mesmo quando apenas a minoria consegue emprego a partir da implantação de um empreendimento hoteleiro nessas regiões mais esquecidas.

Quando indagados sobre o motivo que levou ao empreendimento a criar o Programa Berimbau, os entrevistados pareceram um pouco inocentes, ao colocar como possíveis razões: "para ajudar agente" e "para treinar mão de obra". 
Quanto às ações do Programa, os entrevistados enfatizaram as atividades relacionadas à educação e à geração de emprego e renda. A implantação de duas escolas de informática, a alfabetização de adultos por voluntários da região, a manutenção da escola Meninos do Porto e os cursos de formação profissional em atividades relativas à hotelaria envolvendo parceria com o SENAC e o Instituto de Hospitalidade, foram às ações mais freqüentemente citadas como as mais importantes do Programa.

Constatou-se que as atividades de apoio à cultura, desenvolvidas pelo programa, não eram citadas de forma espontânea. Já com perguntas diretas sempre surgiam as apresentações de roda de samba e de capoeira, "que já tinha se perdido e reavivou novamente", que acontecem com regularidade na Vila Nova da Praia, no empreendimento.

Durante as entrevistas aos representantes da administração do empreendimento, observou-se, que a administração da Costa do Sauípe reconhece que a implantação do empreendimento causou fortes impactos nas comunidades do entorno, segundo B.A.N., "um empreendimento desse porte não podia se tornar uma ilha de prosperidade cercada de miséria por todo lado" e que o principal motivo da criação do Programa Berimbau foi a reação da comunidade a esses impactos "era preciso, de imediato, mostrar ações concretas com vistas a conquistar a credibilidade dos moradores".

Quando procurado o poder público, tanto estadual quanto dos municípios de Mata de São João e Entre Rios, para obter informações sobre o Programa observou-se que estes se encontravam à margem do Programa. Existia o conhecimento do Programa, mas não era apoiado, nem se tinham feito estudos ou pesquisas para saber das mudanças provocadas, nas comunidades do entorno da Costa do Sauípe, pela implantação e desenvolvimento do Programa.

Com o desenvolvimento do Programa, se conseguiu que a população mudasse da atitude de desespero, em que se encontrava, para uma atitude positiva em que pudesse realizar sua capacidade de ajudar-se si mesma.

A real relevância do Programa não está nos seus resultados físicos, medíveis, mas no que os moradores conseguiram mudar em relação ao seu comportamento, ao seu senso de responsabilidade e crenças. Os próprios indivíduos mudaram, como resultado de experiências e de mudanças que, para eles, foram fundamentais.

No desenvolvimento do Programa, ocorreram mudanças verdadeiras e duradouras nos participantes, dentro de um curto período de tempo. Os moradores melhoraram no conhecimento de si mesmos e dos outros, na conduta e na motivação. Isto foi percebido por $66 \%$ dos respondentes, embora $24 \%$ pense que as relações entre os moradores não melhoraram e $10 \%$ não saibam responder a essa pergunta.

Hoje os moradores estão tomando para si a responsabilidade de continuarem com o projeto indefinidamente. Sabem que para isso dependem do esforço cooperativo de muita gente. Aqueles que haviam estado isolados geográfica ou voluntariamente se reuniram em volta de uma causa comum, que poderia beneficiar a todos no entorno da Costa do Sauípe.

A responsabilidade foi se difundindo, surgiram novos líderes. A satisfação e a autoconfiança obtidas trabalhando em conjunto prepararam a população para enfrentar pro- 
blemas cada vez mais difíceis, num processo de crescimento constante, na luta para adquirir novo padrão de vida.

Três anos após seu lançamento, o Programa, já não apresenta o mesmo fôlego nem tem um orçamento tão folgado quanto no início das operações, mas conseguiu manter em funcionamento aqueles projetos melhor acolhidos pela comunidade.

Continuam em funcionamento as cooperativas Coopevales e Verdecoop, responsáveis pela Central de Abastecimento e da Usina de Biodegradação Acelerada com uma tecnologia desenvolvida pela Bioexton, empresa incubada na Universidade de Uberaba (MG). A técnica consiste na utilização de um biodigestor que acelera a decomposição da matéria orgânica. O processo tradicional requer aproximadamente 90 dias para decompor o lixo orgânico. Com o biodigestor, o mesmo resultado é obtido em quatro dias.

A cadeia de produção e distribuição de artesanato já está consolidada e funciona sob a administração de cinco associações de artesãos. O espírito de equipe desenvolvido entre os trabalhadores é um dos grandes responsáveis pelo fomento do artesanato local. Isso porque, no Centro de Artesanato, as pessoas trabalham juntas em tempo integral, o que facilita a interação, a troca de informações e a padronização da produção. Também se encontram em pleno funcionamento a Escola de Produção, na Vila Sauípe, e o Centro Comunitário de Porto Sauípe. Continuam sendo realizadas ações de educação e de capacitação, como a Escola Meninos do Porto, BB educar, cursos de costura e as duas escolas de informática; e de apoio aos grupos culturais da região, que envolvem os grupos de teatro, de capoeira, de samba de roda e de maculelé.

Tanto durante as entrevistas, quanto na análise dos questionários, ficou evidente que as ações que tiveram um maior efeito na comunidade foram as dirigidas à educação e capacitação e à geração de emprego e renda. Dentre as mais variadas respostas, se observou que para o $62 \%$ das pessoas que responderam aos questionários o mais importante que aconteceu por causa do Programa foi a geração de empregos, para $24 \%$ foram as oportunidades de capacitação, para o $8 \%$ foi a inclusão digital.

Em geral todos se mostraram muito satisfeitos, tanto com o Programa, quanto com o empreendimento, principalmente pela geração de trabalho e renda, e pela oferta de capacitação técnica. Porém, observa-se uma certa fragilidade quando se pensa na sustentabilidade em longo prazo das atividades socioeconômicas e de preservação ambiental implementadas no âmbito do programa, devido, principalmente à pouca capacitação técnica e operacional, das lideranças locais, para administrar e monitorar os projetos em andamento.

Diante destes resultados, evidencia-se a necessidade de garantir a continuidade do Programa, o que pode ocorrer a partir do acompanhamento técnico-financeiro, por parte da Sauípe S.A., durante a fase de sedimentação do Programa.

\section{CONSIDERAÇÕES FINAIS}

Atualmente, ganham destaque nos estudos relacionados com a atividade turística palavras como: cidadania, sustentabilidade, responsabilidade social e desenvolvimento 
regional, entre outras. No entanto, essas palavras estarão fadadas ao desgaste se não vierem acompanhadas de medidas efetivas de transformação da realidade social.

Para sua sustentabilidade em longo prazo as empresas turísticas se vêm obrigadas a assumir responsabilidade social, já que somado ao poder econômico vem a responsabilidade com o entorno. Neste contexto, não é suficiente limitar-se ao uso de tecnologias modernas que não prejudiquem o meio ambiente. A responsabilidade social é muito mais complexa: vai desde a gestão econômica da empresa, até a proteção do meio ambiente, passando por vários aspectos sociais, implicando não somente em ações isoladas, mas em uma atitude e uma orientação estratégica enraizadas em toda a empresa.

No entanto, a mentalidade das empresas turísticas e até de muitos turistas, de oferecer e obter tudo ao preço mais baixo possível, e o alto grau de qualidade que requer o setor, exercem uma grande pressão sobre os destinos, piorando as condições sociais nessas regiões.

É necessário impedir que a pressão do mercado leve a idéia de que o cumprimento da responsabilidade social implica uma desvantagem competitiva para a empresa. É importante informar e sensibilizar os clientes com relação à importância da responsabilidade social de forma que possam tomar decisões responsáveis sobre suas viagens, fomentando, assim, o crescimento do mercado do turismo mais justo.

Criado para ser um grande centro de hospedagem e lazer, a Costa do Sauípe se deparou com a carência das comunidades vizinhas como um desafio ao exercício da responsabilidade social. Assim, com o objetivo de promover o desenvolvimento autosustentável das comunidades, o Berimbau nasceu de uma ampla discussão com as

comunidades a serem atendidas.

Os resultados obtidos deixaram entrever que existe uma considerável necessidade de melhora da responsabilidade social no setor de turismo, já que ao mesmo tempo em que o turismo afeta uma amplia gama de fatores sociais e ecológicos, depende muito mais da sua boa reputação do que as empresas de outros setores.

Apesar do rigor utilizado nos procedimentos empregados, a pesquisa apresentou algumas limitações. Na fundamentação teórica, por ser a Responsabilidade Social no Turismo, um tema ainda pouco abordado, a escassez de literatura foi um fator limitador.

Uma fator limitante da pesquisa diz respeito à impossibilidade de se generalizar os resultados obtidos, por se tratar de um estudo de caso e pela especificidade do tema de pesquisa, sendo que os resultados da aplicação do Programa em outras regiões pode variar devido a uma série de fatores conjunturais e até mesmo estruturais das comunidades afetadas.

Sugere-se a formatação de um modelo básico de reaplicação do Programa Berimbau para seu aproveitamento em outros empreendimentos, permitindo a difusão da tecnologia social embutida no Programa Berimbau, proporcionando soluções criativas e de baixo custo, com o objetivo de transformar positivamente a realidade de muitas pessoas, como forma de luta contra a injustiça social. 


\section{REFERÊNCIAS}

Araújo, Lindemberg Medeiros de (2006): "Participação sóciopolítica no planejamento turístico". In Turismo - Visão e Ação. Vol. 8 - n.1 - jan./abr. Itajaí: Univali, pp. 153-164.

Ashley, Patrícia Almeida (2002): Ética e responsabilidade social nos negócios. São Paulo, Saraiva.

Beni, Mário Carlos (2006): Política e planejamento de turismo no Brasil. São Paulo: Aleph, (Série Turismo).

Daft, Richard L. (1999): Administração. $4^{\mathrm{a}}$ ed. Rio de Janeiro: Ed. LTC.

DESENCOM, Consultores Associados (2005): "Relatório de Acompanhamento do Programa Berimbau", 1 CD-ROM.

ETHOS, Instituto Ethos de Empresas e Responsabilidade Social (2003): Criando Valor: $\mathrm{O}$ business case para sustentabilidade em mercados emergentes.Disponível em: $<$ http://www.ethos.org.br. 2003>. Acesso em: 15 de jun. de 2006.

Fontes, Andréa de Souza (2005): A Responsabilidade Social Empresarial em questão: o pensamento pedagógico do Instituto Ethos.Disponível em: <www.uff.br/trabalhonecessario /Andrea.htm>. Acesso em: 31 de mar. de 2006

Gil, Antônio Carlos (1999): Métodos e técnicas de pesquisa social. 5a ed. São Paulo: Atlas.

Godoy, Arilda Schmidt (1995): "Pesquisa qualitativa: tipos fundamentais", Revista de Administração de Empresas. v. 35, n. 3, mai/jun. São Paulo, pp. 20-29.

Mattar, Fauze Najib (1996): Pesquisa de marketing. São Paulo: Atlas.

Guedes, Rita de Cássia (2000): Responsabilidade social e cidadania empresariais: conceitos estratégicos para as empresas face à globalização. Dissertação de Mestrado em Administração de Empresas. São Paulo: PUC/SP, 170 pp.

Hayes, Samuel Perkins (1996): Avaliação de projetos de desenvolvimento. Rio de Janeiro: FGV.

Oliveira, J. A. (1984): "Responsabilidade social em pequenas e médias empresas", Revista de Administração de Empresas, v. 24, n. ${ }^{\circ}$, p. 203-210, out./dez. São Paulo.

OMT, Organização Mundial de Turismo (2006): World Tourism Barometer.

Disponível em <http://www.world-tourism.org/> Acesso em: 10 de abr. de 2006.

Rico, Elizabeth de Melo (2004): A responsabilidade social empresarial e o Estado: uma aliança para o desenvolvimento sustentável. São Paulo Perspec., São Paulo, v. 18, n. 4. Disponível em: $<\mathrm{http}: / / w w w . s c i e l o . b r / s c i e l o . p h p ?$ script=sci_arttext\&pid=S010288392004000400009\&lng=en\&nrm=iso>. Acesso em: 15 Feb 2007.

Scour, Henry Robert (1998): Poder, cultura e ética nas organizações. Rio de Janeiro: Campos.

Swarbrooke, John (2000): Turismo Sustentável: setor público e cenários geográficos. Vol.3. São Paulo: Aleph (Série Turismo). 
Voigt, L. (2006): Investimento deve Beneficiar Comunidade em Primeiro Lugar. Disponível em: <www.fides.org.br> acesso em 3 de abril de 2006. 